\title{
Harmonics reduction in standalone DFIG-DC system by shunt active filter controlled in stator flux reference frame
}

\author{
HIMANSHU MISRA* ${ }^{*}$ and AMIT KUMAR JAIN \\ Department of Electrical Engineering, Indian Institute of Technology Delhi, New Delhi 110016, India \\ e-mail: himanshu00129@gmail.com
}

MS received 15 April 2017; revised 2 January 2018; accepted 18 January 2018; published online 22 May 2018

\begin{abstract}
The presence of diode rectifier in standalone Doubly Fed Induction Generator-Direct Current (DFIGDC) system leads to considerable current, voltage and torque harmonics and requires reactive power from the machine. A unique shunt active filter arrangement is proposed for addressing these requirements. The DC Link of DFIG-DC itself acts as input to shunt active filter and there is no requirement of creating and regulating a separate one. Since the stator flux reference frame is known in FOC of DFIG-DC system; the same can be used as PLL for the generation of current references for harmonics and reactive compensation in active filter control scheme. Hence, the AC voltage sensing is not needed in the proposed active filter control. In this paper, it is shown that current, voltage and torque harmonics are reduced with the help of shunt active filter, which have lower rating compared to the rotor side converter. The proposed scheme is verified by detailed experiments on a $5.5 \mathrm{~kW}$ slip-ring induction machine.
\end{abstract}

Keywords. Doubly fed induction generator; standalone; DC voltage regulation; shunt active filter; harmonics control.

\section{Introduction}

DC generation has various advantages over AC generation, but most of the power generation through rotating prime mover is in AC. It can be converted into constant DC voltage source with the help of diode rectifier or power electronics converter. In this way, the benefits of DC generation can be utilized. AC-DC conversion by diode rectifier leads to harmonics pollution in the system. This results in heating, torque ripple and power loss in the machine. Hence, it degrades the life of mechanical parts and winding insulation of machines. Therefore, in this AC-DC conversion system, the prime concern is to reduce harmonic and one of the ways is to use active filter.

The various advantages of DC technology and its review of future smart distribution grid are reported in [1]. The concept of the DC-micro grid is also becoming popular and the review on its control strategies is presented in [2]. For obtaining the advantages of DC over AC, DFIG generation can also be converted into DC generation by diode rectifier. Recently, the DC-grid connected DFIG-DC system is reported with frequency and torque regulation [3-8]. Operation and design issue of DFIG in DC-net interface is reported in [3]. An inner control based frequency and torque regulation of DFIG-DC system is established in [4]. A sensorless observer based algorithm for the slip angle calculation is proposed using air gap power in [5]. For

*For correspondence improving the performance of Doubly Fed Induction Generator-Direct Current (DFIG-DC) system, torque ripple reduction using PI-R controller is elaborated in [6]. In DCgrid connected DFIG, a method of harmonic minimization is proposed using shunt active filter in [7]. A field weakening control for efficiency optimization is presented in [8]. In [8], the frequency is varied over the wide range by flux loop without exceeding the rated flux. The control of DFIGDC for standalone or isolated DC loads is recently reported in [9-12]. But no work is reported yet for harmonics reduction in standalone DFIG-DC system. In this paper, a unique active filter arrangement and its control for minimization of harmonics is proposed. Various techniques of the active filter control are described in [13, 14]. Active filter system implementation is discussed in [15]. A flux based hysteresis controller for parallel active filter control is presented in [16]. Synchronous reference frame based controller is applied for series active filter control in [17]. Implementation issues are discussed in [18].

In this paper, a method for minimization of harmonics in stand-alone DFIG-DC generation system is proposed. The minimization of harmonics is achieved with the addition of unique shunt active filter arrangement to the system. The arrangement is unique, since the active filter does not require creation and regulation of separate dc link for its operation. The dc link of DFIG-DC system itself can serve the purpose. In the proposed control, the switching of active filter is achieved on a hysteresis rule-based current PWM scheme to achieve high control bandwidth. Active filter 
control requires PLL for generation of current reference for harmonics and reactive power compensation. The technique used is synchronous reference generation (SRF) based approach. Another advantage of the arrangement is that, since the stator flux oriented FOC is used for the control of standalone DFIG-DC, the same reference frame can also be used as PLL and therefore, there is no need for separate voltage sensing at the input of the active filter. The DC link voltage is regulated by RSC, and it is shared with load and the active filter. Both active filter and RSC are partially rated converters.

The salient points of the proposed work are,

1) Shunt active filter is controlled in stator flux reference frame of the DFIG.

2) No separate DC source required for shunt active filter.

3) DC link is created and maintained by RSC. For Active filter scheme is independent of DC voltage regulation.

4) No voltage sensing is required for active filter control scheme, as known stator flux reference frame is serving the purpose.

5) Three PI controllers are required in DFIG-DC system for regulation of DC voltage control as well as rated flux and frequency.

6) The hysteresis current control is used in active filter for harmonic mitigation.

System description of DFIG-DC system with shunt active filter is described in section 2. Need of filtering is explained in section 3. Control philosophy is illustrated in section 4 for both standalone DFIG-DC system and the proposed active filter. Experimental set-up is described in section 5, whereas, the performance of the proposed scheme is verified experimentally and results are presented in section 6. The conclusions are provided in section 7.

\section{System description and modelling}

\subsection{Standalone DFIG-DC system with shunt active filter}

The structure of the standalone DFIG-DC system with shunt active filter is shown in figure 1. In this arrangement, the stator of DFIG is connected with diode rectifier and the DC-link capacitor is shared between active filter, RSC, and load. Shunt active filter is connected through a step-down transformer for enabling common DC-link sharing and isolation. In this arrangement, the leakage reactance of transformer is used as filter for active filtering scheme. Therefore, limited harmonics reduction is achieved. The stator side converter is not used due to the $\mathrm{kVA}$ rating of this converter. As rated frequency and voltage is maintained at stator side, leads to one per unit kVA rating of the stator side converter (rated voltage and rated current) which is costly solution as compared to uncontrolled three phase diode rectifier. While power handled by active filter is very

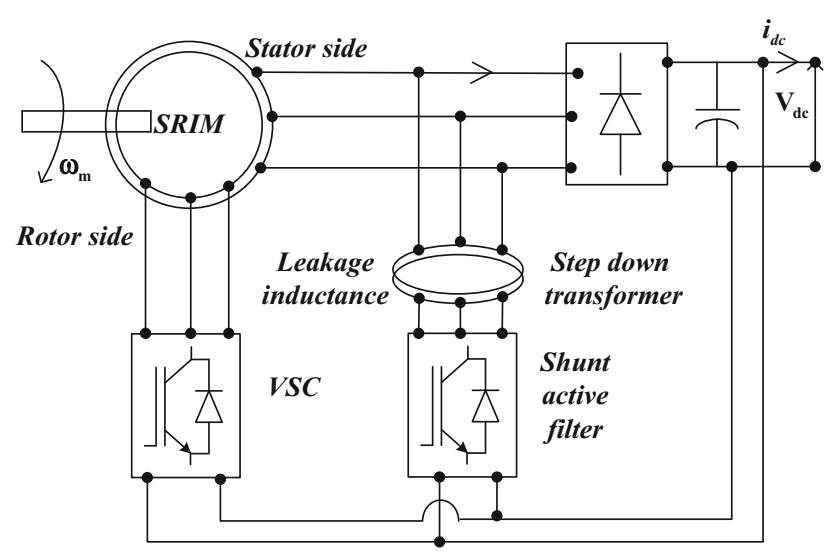

Figure 1. Standalone DFIG-DC system with shunt active filter.

less and equal to harmonics power. If reactive power compensation is also done then $\mathrm{kVA}$ rating of shunt active filter will increase little bit but remain low as compared to stator side converter.

\subsection{Modelling equations}

DFIG-DC system can be represented by modeling equation (1)-(8) in stator flux reference frame [19-23]. Rotor voltage equation in stator flux reference frame is expressed in (1) and (2). Stator flux based magnetizing current reference can be found by (3) which is a stator $v_{s q}$ equation. Other important relations are given in (4) to (8).

$$
\begin{gathered}
v_{r d}=\left[\begin{array}{c}
R_{r} i_{r d}+\sigma L_{r} \frac{d i_{r d}}{d t}-\sigma L_{r}\left(\omega_{s}-\omega_{e}\right) i_{r q} \\
+(1-\sigma) L_{r} \frac{d i_{m s}}{d t}
\end{array}\right] \\
v_{r q}=\left[\begin{array}{l}
R_{r} i_{r q}+\sigma L_{r} \frac{d i_{r q}}{d t}+\sigma L_{r}\left(\omega_{s}-\omega_{e}\right) i_{r d} \\
+(1-\sigma) L_{r}\left(\omega_{s}-\omega_{e}\right) i_{m s}
\end{array}\right] \\
i_{m s}=\left[\frac{v_{s q}}{L_{o} \omega_{s}}+\frac{i_{r q}}{T_{s} \omega_{s}}\right] \\
T_{r q}=-\frac{i_{m s}}{d t}+i_{m s}=\frac{v_{s d}}{R_{s}}\left(1+\sigma_{s}\right)+i_{r d} \\
L_{o} \quad \text { and } \quad i_{m s}=\frac{L_{s}}{L_{o}} i_{s d}+i_{r d} \\
T_{s}=\frac{L_{s}}{R_{s}}, \sigma_{s}=\frac{L_{s}}{L_{o}}-1 \quad \text { and } \quad \sigma=1-\frac{L_{o}^{2}}{L_{s} L_{r}} \\
\bar{v}_{r}=\frac{3}{2} v_{r} \_p h p=\frac{3}{2} \frac{m_{a} V_{d c}}{2}=\frac{3}{4} m_{a} V_{d c}
\end{gathered}
$$

where $m_{a} \propto$ slip, and harmonics 


$$
M_{d}=-\frac{2}{3} \frac{P}{2} \frac{L_{o}^{2}}{L_{s}} i_{m s} i_{r q}=\frac{2}{3} \frac{P}{2} L_{o} i_{m s} i_{s q}
$$

\section{Need of filtering}

The presence of diode rectifier at the stator side leads to distortion of current and voltage waveforms in the stator circuit. The major effect of these distorted waveforms is discussed in the following sub-sections.

\subsection{Harmonics}

The distorted stator waveform can be analyzed, by the help of Fourier series, by extracting its fundamental and harmonics components. The harmonics content in the voltage and current waveforms do not play any constructive role in the system. It causes power loss, heating, degradation of insulation, and torque pulsation inside the machine. Hence, the filtering of the harmonics is needed.

\subsection{Torque ripple}

In this system, due to the principle of induction, harmonics reflects on the rotor circuit. Since electromagnetic torque of the DFIG is proportional to the product (8) of $i_{m s}$ and $i_{r q}$, it results in the torque ripple. These ripples are harmful for the mechanical parts of the machine and cause shaft twist, bearing failure, etc.

Torque pulsation in the induction machine is mainly due to the interaction of fundamental stator flux and rotor harmonics current and vice versa. The main source of harmonics in the
Therefore, nature of torque considering the lower harmonics can be analyzed as follows

$$
M_{d}=\frac{2}{3} \frac{P}{2} L_{o} \operatorname{Im}\left(i_{s \alpha \beta} i_{r \alpha \beta}^{*}\right)
$$

Replace the stator current in terms of the rotor and magnetizing current, and convert it into stator flux reference frame. Therefore, torque can be rewritten as (10).

$$
\begin{gathered}
M_{d}=\frac{2}{3} \frac{P}{2} \frac{L_{o}^{2}}{L_{s}} \operatorname{Im}\left(i_{m s d q}^{+} i_{r d q}^{+*}\right) \\
i_{m s d q}^{+}=i_{m s d q+}^{+}+i_{m s d q 5-}^{5-} e^{-j 6 \omega_{s} t}+i_{m s d q 7+}^{7+} e^{j 6 \omega_{s} t} \\
i_{r d q}^{+}=i_{r d q+}^{+}+i_{r d q 5-}^{5-} e^{-j 6 \omega_{s} t}+i_{r d q 7+}^{7+} e^{j 6 \omega_{s} t}
\end{gathered}
$$

On substituting currents in (10), using (11) and (12), and by further simplifying the torque equation, it can be expressed as (13), where torque ripple is visible in terms of sine and cosine.

$$
M_{d}=\frac{2}{3} \frac{P}{2} \frac{L_{o}^{2}}{L_{s}}\left[\begin{array}{c}
M_{d, d c}+M_{d, \sin 6} \sin 6 \omega t+M_{d, \cos 6} \cos 6 \omega t \\
+M_{d, \sin 12} \sin 12 \omega t+M_{d, \cos 12} \cos 12 \omega t
\end{array}\right]
$$

The components of electromagnetic torque (13) are given in (14). From (14), it can be observed that the interaction of same frequency of orthogonal $d q$-axes rotor currents and magnetizing currents result in the DC component of torque, and the interaction of different frequency rotor current with magnetizing current results the oscillatory torque components. The resultant frequency of the torque oscillation is considered as the sixth order since its magnitude is higher than twelfth order terms (which is the result of higher harmonics component) as shown in (14).

$$
\left[\begin{array}{r}
M_{d, d c} \\
M_{d, \sin 6} \\
M_{d, \cos 6} \\
M_{d, \sin 12} \\
M_{d, \cos 12}
\end{array}\right]=\left[\begin{array}{cc}
+i_{m s q+}^{+} & -i_{m s d+}^{+} \\
-i_{m s d 5-}^{5-}+i_{m s d 7+}^{7+} & -i_{m s q 5-}^{5-}+i_{m s q 7+}^{7+} \\
+i_{m s q 5-}^{5-}+i_{m s q 7+}^{7+} & -i_{m s d 5-}^{5-}-i_{m s d 7+}^{7+} \\
0 & 0 \\
0 & 0
\end{array}\right.
$$

$$
\begin{array}{cc}
+i_{m s q 5-}^{5-} & -i_{m s d 5-}^{5-} \\
i_{m s d+}^{+} & i_{m s q+}^{+} \\
i_{m s q+}^{+} & -i_{m s d+}^{+} \\
+i_{m s d 7+}^{7+} & +i_{m s q 7+}^{7+} \\
+i_{m s q 7+}^{7+} & -i_{m s d 7+}^{7+}
\end{array}
$$$$
\begin{aligned}
& +i_{m s q 7+}^{7+} \\
& -i_{m s d+}^{+} \\
& +i_{m s q+}^{+} \\
& -i_{m s d 5-}^{5-} \\
& +i_{m s q 5-}^{5-}
\end{aligned}
$$$$
\left.\begin{array}{c}
-i_{m s d 7+}^{7+} \\
-i_{m s q+}^{+} \\
-i_{m s d+}^{+} \\
-i_{m s q 5-}^{5-} \\
-i_{m s d 5-}^{5-}
\end{array}\right]\left[\begin{array}{c}
i_{r d+}^{+} \\
i_{r q+}^{+} \\
i_{r d 5-}^{5-} \\
i_{r q 5-}^{5-} \\
i_{r d 7+}^{7+} \\
i_{r q 7+}^{7+}
\end{array}\right]
$$

machine is the distorted nature of terminal voltages; it may be six-stepped or Pulse Width Modulated (PWM). In the case of six-stepped applied voltage, predominate torque ripple will appear at a sixth harmonic frequency and at the pulsed frequency for PWM applied voltage. For higher pulse frequency PWM voltage, torque ripple will also have high frequency, hence it may be neglected.
It can also be understood in a different way that, as in the DFIG-DC system, due to the presence of diode rectifier at the stator side, a quasi-square voltage appears at stator terminals which can lead to lower order torque ripple. The interaction of stator fundamental flux and rotor harmonics current will create dominant torque ripple, whereas the effect of PWM rotor terminal voltage is neglected due to higher switching 


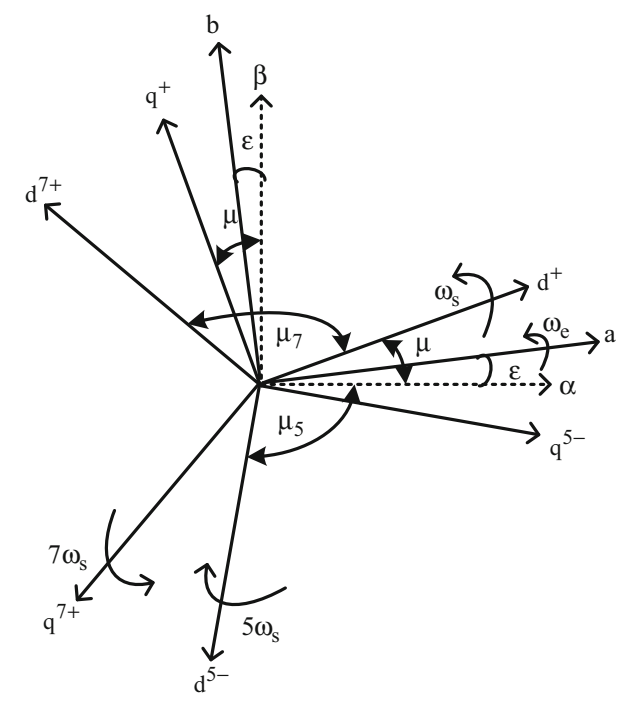

Figure 2. Phasor diagram of dominant harmonics in standalone DFIG-DC system.

frequency $(5 \mathrm{kHz})$. Hence, the major component of pulsating torque is sixth order pulsating component derived from fifth and seventh order harmonic components. Phasor diagram in figure 2 shows the direction of rotations of the fundamental and dominant harmonics quantities.

\section{Control philosophy}

Control block diagram of stand-alone DFIG-DC system with shunt active filter is shown in figure 3. DFIG is being controlled in stator flux oriented control for maintaining the constant DC-link voltage. The synchronous reference frame theory is used in the control of shunt active filter.

\subsection{Standalone DFIG-DC system control}

In this system, DFIG-DC system is being controlled in stator flux reference frame for output DC voltage regulation of the diode rectifier. A matching transformer is used for stepping down stator voltage, so that same DC-link can be shared with partially rated RSC, for a higher turn ratio based slip ring induction machine. Stator voltage and frequency control of standalone DFIG-AC is a well-known concept [19-24]. In almost all these reported works, the output stator voltage is regulated by d-loop (flux) and torque is controlled by q-loop through sensed $i_{s q}$. Recently a stand-alone DFIG-DC system control is presented in [9], wherein the dc link voltage $V_{d c}$ and load are regulated from q-loop and frequency regulation is done by d-loop.

Similar to [20], the field oriented control is used for output DC-voltage regulation of diode rectifier through RSC [9], but the role of voltage PI-controller is interchanged from flux reference generation of d-loop to torque reference generation of q-loop. In this work, $V_{d c}$ and load are controlled by current q-loop and flux demand is managed from current d-loop as shown in figure 3. The output of $V_{d c}$ PI-controller becomes the $i_{r q}$ reference (torque information). The flux reference is kept constant initially, but after settling of flux loop, it is derived from (3). The detailed analysis with dc voltage regulation of standalone DFIG-DC system is given in [12]. Since, standalone DFIG-DC-system is being operated at constant stator frequency reference but due to harmonics at the stator side, resultant frequency is oscillatory in nature which is the superimposition of harmonics on the fundamental frequency. Therefore, the minimization of harmonics is necessary for smooth operation of the machine.

\subsection{Proposed shunt active filter control}

Current harmonics of the presented system can be easily controlled through shunt active filter. In this paper, the active filter is controlled in stator flux reference frame by transforming the input diode currents into $\mathrm{d}-\mathrm{q}$ frame. Its $\alpha-\beta$ to $d-q$ transformation matrix is given in (15) where, the $\mathrm{d}$-axis current reflects the stator side reactive component and q-axis current shows the active component. As it is optional to supply reactive power demand by shunt active filter, but sharing of the reactive component will lead to better utilization of both converters and machine.

$$
\left[\begin{array}{c}
i_{s d} \\
i_{s q}
\end{array}\right]=\left[\begin{array}{cc}
\cos \mu & \sin \mu \\
-\sin \mu & \cos \mu
\end{array}\right]\left[\begin{array}{c}
i_{s \alpha} \\
i_{s \beta}
\end{array}\right]
$$

The control block diagram of shunt active filter is shown in figure 3, where, four line currents (two stator, and two diode currents) are sensed for the control scheme. In this system, the initially the input current of diode rectifier is transformed to a synchronous reference frame ( $\mathrm{d}-\mathrm{q}$ frame) by stator flux angle matrix (15), then later these quantities are passed through low pass filter with cut-off frequency of $5 \mathrm{~Hz}$. This transformation will remove all higher order ripple components from $\mathrm{d}-\mathrm{q}$ axis current and passes only DC part of the current. The $\mathrm{d}-\mathrm{q}$ to $\alpha-\beta$ inverse transformation matrix (16) is used for generating $\alpha-\beta$ axis AC reference currents. It is further transformed to three phase AC reference currents for only harmonic current control. Reactive power sharing can also be achieved by keeping daxis current zero. Hence, modified matrix for reactive power control can be written as (17) where, $i_{\text {sd_fil }}^{\prime}=0$.

$$
\left[\begin{array}{c}
i_{s \alpha}^{\prime} \\
i_{s \beta}^{\prime}
\end{array}\right]=\left[\begin{array}{cc}
\cos \mu & -\sin \mu \\
\sin \mu & \cos \mu
\end{array}\right]\left[\begin{array}{l}
i_{s d_{\text {f f }}^{\prime}} \\
i_{s q \_f i l}^{\prime}
\end{array}\right]
$$

Comparison of AC current reference quantities with sensed currents gives the information of harmonic 


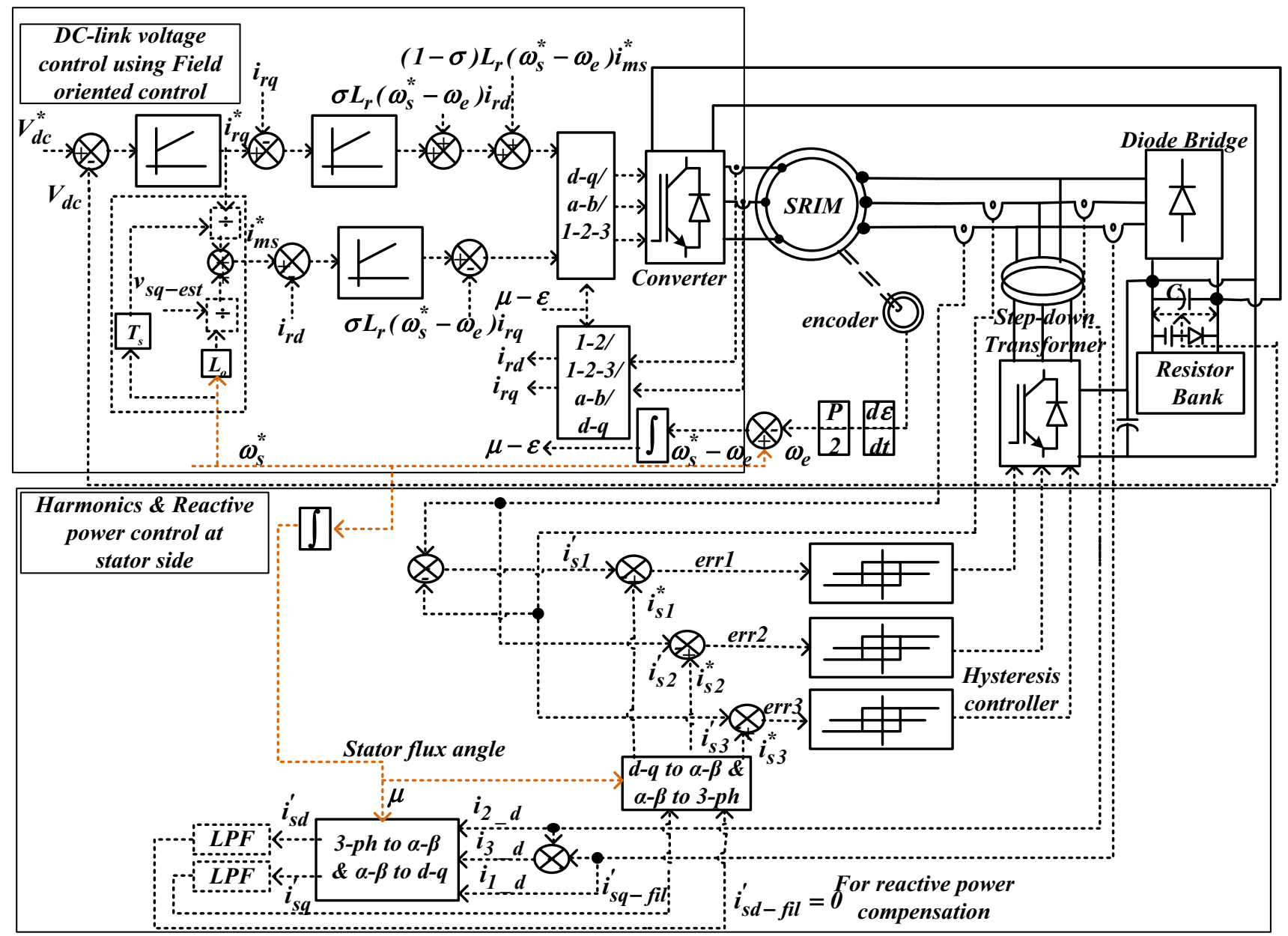

Figure 3. Block diagram of standalone DFIG-DC system with shunt active filter.

component with reactive power demand. These errors are fed to a hysteresis-based PWM signal generator to produce final switching signals for the control of shunt active filter as shown in figure 3. Since, stator flux angle itself is used as PLL, which is directly available from FOC, helps in the reduction of voltage sensors in this control scheme.

$$
\left[\begin{array}{c}
i_{s \alpha}^{\prime} \\
i_{s \beta}^{\prime}
\end{array}\right]=\left[\begin{array}{cc}
\cos \mu & -\sin \mu \\
\sin \mu & \cos \mu
\end{array}\right]\left[\begin{array}{r}
0 \\
i_{s q}^{\prime} \\
\end{array}\right]
$$

The active filter is connected using a step-down transformer on the AC side. It enables DC-link voltage sharing and isolation from $\mathrm{AC}$ side. In addition to this, the leakage inductance of transformer supports filtering action. Due to common DC-link, a separate DC-link voltage control of active filter is not needed, unlike the usual control method. Sharing of reactive power between the active filter (stator side) and rotor side converter can be decided according to converter ratings and machine MMF property. These parameters are basically provided by the manufacturer. The harmonics elimination of DFIG-DC system is shown in figure 4 where, active filter is supplying the harmonics part

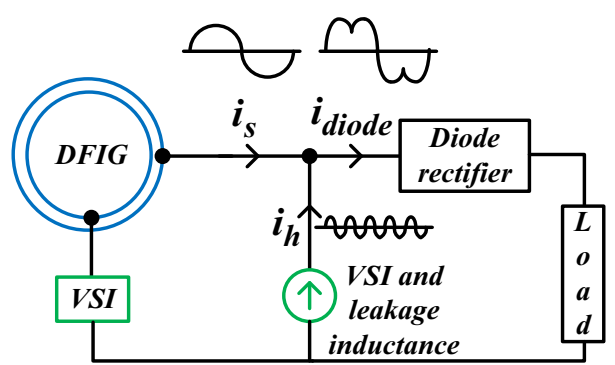

Figure 4. Harmonics elimination in the standalone DFIG-DC system.

of load current such that stator currents approach towards sine wave (19). It can be understood by mathematics as follows

$$
\begin{gathered}
i_{s}+i_{h}=i_{\text {diode }} \\
i_{s \alpha \beta}=i_{s \alpha \beta+} e^{j \omega_{s} t} \\
i_{h \alpha \beta}=i_{s \alpha \beta 5_{-}} e^{-j 5 \omega_{s} t}+i_{s \alpha \beta 7+} e^{j 7 \omega_{s} t}
\end{gathered}
$$




$$
i_{\text {diode }, \alpha \beta}=i_{s \alpha \beta+} e^{j \omega_{s} t}+i_{s \alpha \beta 5-} e^{-j 5 \omega_{s} t}+i_{s \alpha \beta 7+} e^{j 7 \omega_{s} t}
$$

The harmonic current as shown (20) contains 5th and 7th harmonics currents, but during reactive power compensation, nature of harmonic current will modify and it can be written as (22).

$$
i_{h \alpha \beta}=\left[\begin{array}{l}
j\left(i_{s \beta} \cos \omega_{s} t+i\right. \\
+i_{s \alpha \beta 5-} e^{-j 5 \omega_{s} t}+i_{s \alpha \beta 7+} e^{j 7 \omega_{s} t}
\end{array}\right]
$$

In (22), the reactive part of fundamental current is also supplied with harmonic currents through active filter. The input current of diode rectifier shown in (21) contains only the major harmonics components, whereas higher order harmonic components are neglected due to smaller magnitude. However, in the proposed control, a small portion of the higher order harmonics remains in the system after filtering the lower order harmonics. This happens due to smaller coupling inductance between filter and stator, and negligible inductance between point of coupling of active filter and diode rectifier. But these harmonics have less impact on system compared to lower order harmonics. Reduction of it needs the addition of extra inductance in the system which will make system bulky and costly.

\section{Experimental set-up}

Experimental set-up of presented control is shown in figure 5. The DC machine is emulated as a prime mover in speed control mode. Voltage Source Converter (VSC) is connected to the rotor of Wound Rotor Induction Machine (WRIM) and three phase diode rectifier is connected with stator through three phase step-down transformer. Shunt active filter is connected between secondary side of transformer and diode rectifier. Another step-down transformer is connected between shunt converter and the point of common coupling. DC link capacitor is shared with load, RSC and shunt active filter. Virtual battery (created by separate three phase rectifier) is connected in parallel with DC-link for initial voltage build-up. A diode is connected in series with virtual battery for smooth removal of it, after the initial DC-link voltage build up. Two rotor current sensors, one DC link voltage sensor, and an encoder are used for DFIG-DC system control, whereas, four current sensors are used for shunt active filter control. TI TMS320F2407A DSP is used for digital implementation of the control algorithm. It is running at the clock frequency of $40 \mathrm{MHz}$ with a sampling time of 204.35 us.

\section{Results}

Experimental results of the proposed control scheme are presented in this section. Photograph of experimental set-up is given in appendix $\mathrm{A}$ and its specifications are listed in the appendix B. The control algorithm is implemented in the assembly language for better utilization of the processor. The complete program includes armature voltage based speed control of DC machine, field oriented control of standalone DFIG-DC system and stator flux reference frame based shunt active filter control.

\subsection{Standalone DFIG-DC system with active filter}

Standalone DFIG-DC system is being controlled in stator flux reference frame and it is the main control scheme for regulating the DC-voltage. The performance of this system is shown experimentally with and without active filter control in figure 6. In this system, the load is varied in super-synchronous speed (with and without harmonic compensation). Outer-loop $V_{d c}^{*}, V_{d c}$ together with inner

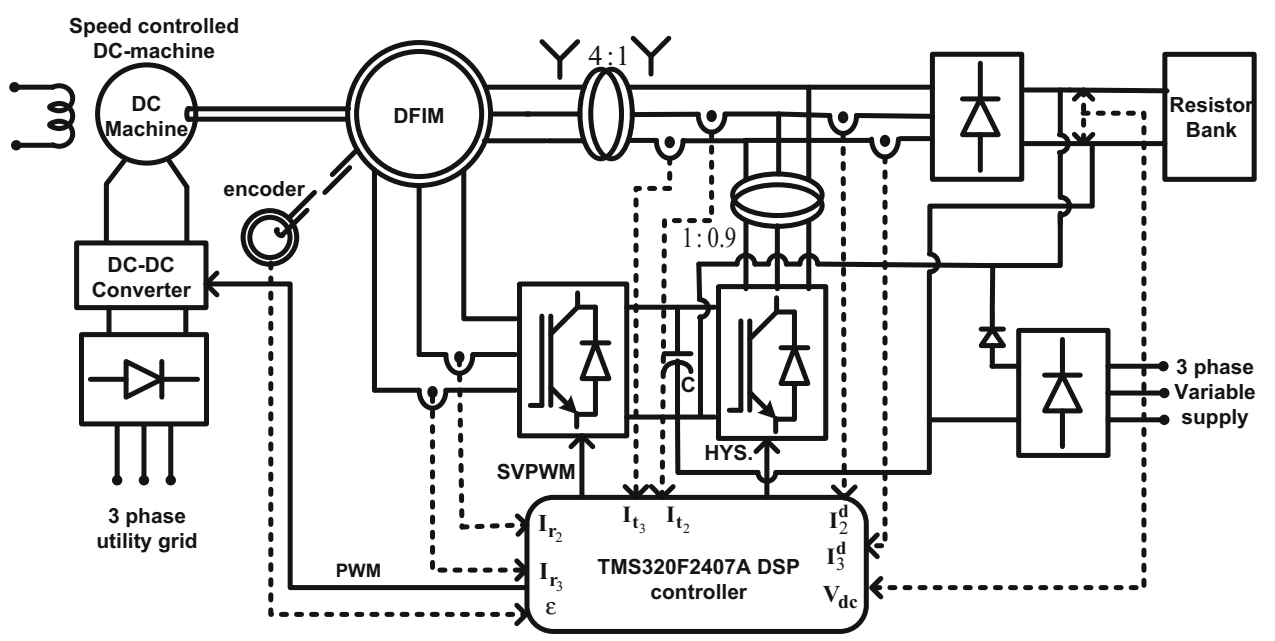

Figure 5. Experimental set-up of standalone DFIG-DC system with shunt active filter. 


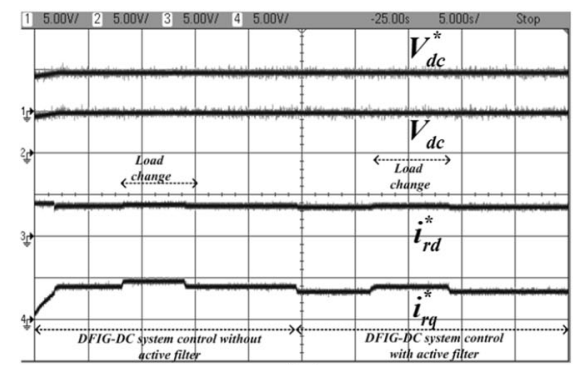

(a)

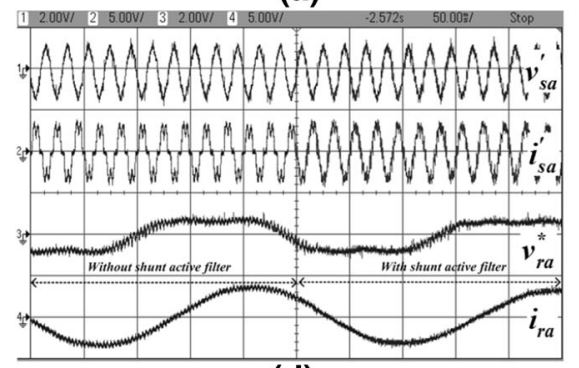

(d)

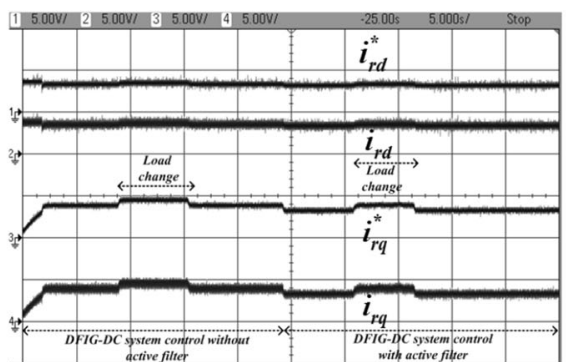

(b)

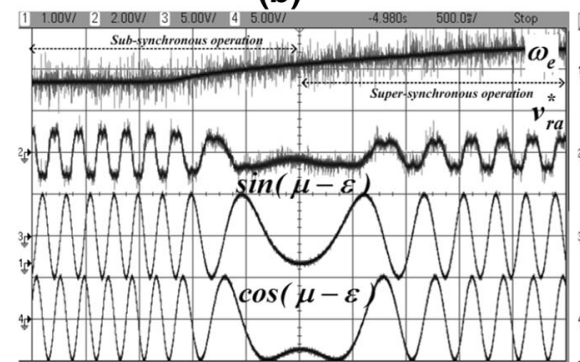

(e)

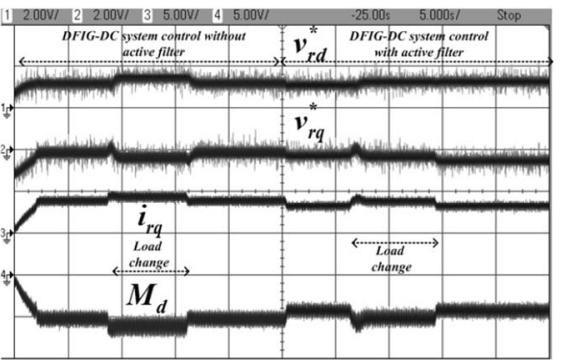

(c)

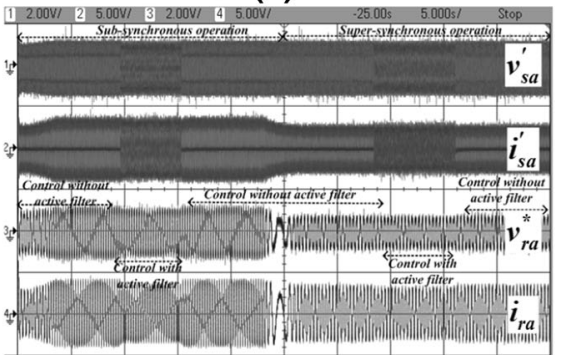

(f)

Figure 6. Experimental results based on performance of standalone DFIG-DC system with and without shunt active filter Scale: $V_{d c}=$ $120 \mathrm{~V} / \mathrm{div}, i_{r d} ; i_{r a} ; i_{r q}=59.4 \mathrm{~A} / \mathrm{div}, M_{d}=17.5 \mathrm{Nm}, V_{s a}{ }^{\prime}=135.52 \mathrm{~V} / \mathrm{div}, i_{s a}{ }^{\prime}=10.39 \mathrm{~A} / \mathrm{Div}, v_{r a}{ }^{*}=39.2 \mathrm{~V} / \mathrm{div}, \omega_{e}=62.8 \mathrm{elect}-\mathrm{rad} \mathrm{per}$ sec/div, Time = (a), (b), (c) $5.0 \mathrm{sec} / \mathrm{div}$ (d) $0.05 \mathrm{sec} / \mathrm{div}$, (e) $0.5 \mathrm{sec} / \mathrm{div}$, and (f) $0.5 \mathrm{sec} / \mathrm{div}$.

loops current quantities are given in figure 6(a) for a step load change. Similarly, the effect of load variation on $i_{r d}{ }^{*}$, $i_{r q}{ }^{*}, i_{r d}, i_{r q}, v_{r d}{ }^{*}, v_{r q}{ }^{*}$ and $M_{d}$ are shown in figure 6(b) and (c). It is shown in the results that, initially the DFIG-DC system is controlled without active filter control and after some time the active filter control is activated. The active filter control is turned on in between main control. Now, the magnitude of rotor current and reference voltages get reduced, while, $V_{d c}, i_{r d}$, and $i_{r q}$ are still tracking their reference properly.

The transition from sub-synchronous speed to the supersynchronous mode of operation is shown in figure 6(e) and (f). The active filter control is turned on, in between in figure 6(d) while, it is turned on and turned off in between each of the modes of operation in figure 6(f). It can be seen that the nature of different waveforms gets improved. Due to a similar effect of speed variation and load variation on control quantities as shown in figure 6(a) to (c), different quantities are selected for showing the complete behavior of the system in figure 6(d) to (f). These figures show the AC nature of rotor circuit and stator side quantities. The sine and cosine of slip angle and carrier based SVPWM rotor reference voltage is shown in figure 6(e). Phase reversal of slip angle and rotor quantities from sub-synchronous to supersynchronous speed is clearly visible in figure 6(e) and (f). In figure 6(e), the cosine of slip angle is leading with the sine of slip angle in subsynchronous mode and vice versa in super-synchronous mode. Rotor power reversal can be understood by the change of slip sign.

\subsection{Shunt active filter control}

Shunt active filter with shared DC-link is controlled in stator flux reference frame for regulating the current harmonics. Input filtering inductor of the diode rectifier (figure 3) is not used in the active filter control. This makes the system less bulky and cheaper. In the proposed control of shunt active filter, the input current of diode rectifier is sensed and transformed to dq reference frame using angle $\mu$ as shown in figure 7(a). It is visible that $\mathrm{d}-\mathrm{q}$ axis currents (channel 1 and channel 2) have 6th order ripple. These lower order ripples produce harmful torque ripple when compared to higher order ripple. Hence, it needs to be regulated. Current references for active filter control are generated by passing $\mathrm{d}-\mathrm{q}$ axis currents from a low pass filter. Corresponding filtered $\mathrm{d}-\mathrm{q}$ axis currents are shown in figure 7(a) (channel 3 and channel 4).

Figure 7(b) shows phase-a currents where $i_{s a}^{\prime}$ is the current before the filter connecting point, $i^{*}{ }_{s a}$ is the reference current for harmonics control and $i_{\text {sa_err }}^{\prime}$ is the current error. This current error is obtained by the difference of sensed stator side current and reference current. In figure 7(b), the active filter control is turned on in between, and it results in near sinusoidal nature of stator side currents, but current drawn by diode rectifier remains same. The current error gets modified with higher order ripple, but it is not exactly zero, due to the limitation of switching frequency $(5 \mathrm{kHz})$ and filtering inductance.

Similarly, figure 7(c) shows the same currents; only error current is replaced by actual active filter current. The 


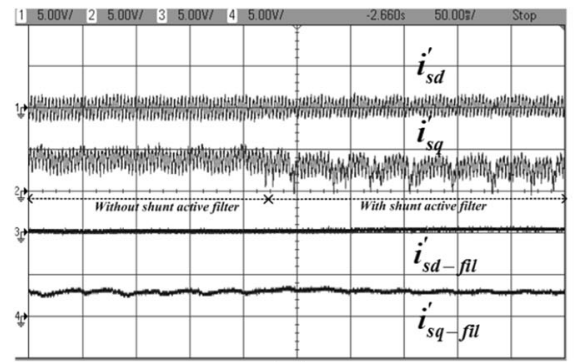

(a)

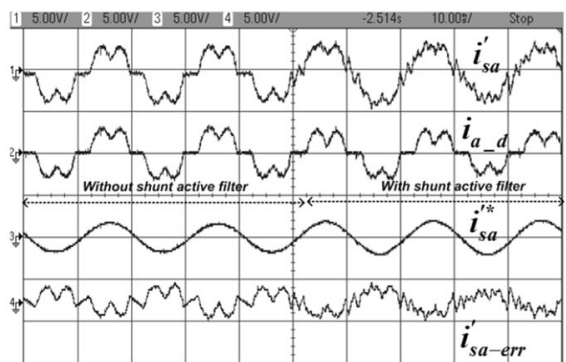

(b)

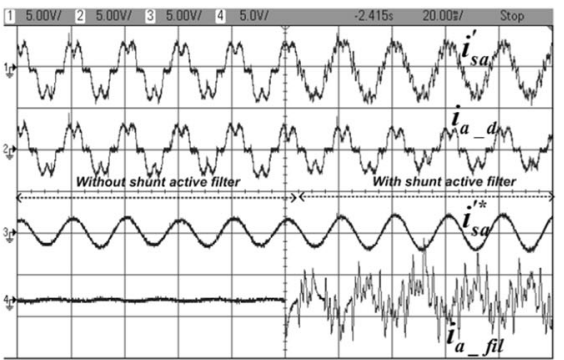

(c)

Figure 7. Experimental results showing the operation of shunt active filter Scale: $i_{s d}{ }^{\prime}, i_{s q}{ }^{\prime}, i_{s d}{ }^{\prime} f i l, i_{s q}{ }^{\prime} f_{i l}, i_{s a}{ }^{\prime}, i_{a_{-} d}, i_{s a}{ }^{*}, i_{s a}{ }^{\prime} e r r=10.39$ $\mathrm{A} / \mathrm{Div}, i_{a_{-} \text {fil }}=5 \mathrm{~A} / \mathrm{Div}$, Time $=$ (a) $0.05 \mathrm{sec} / \mathrm{div}$, (b) $0.01 \mathrm{sec} / \mathrm{div}$, and (c) $0.02 \mathrm{sec} / \mathrm{div}$.

addition of stator side current (channel 1) and active filter current (channel 4) is equal to the input current of diode rectifier (channel 2), hence; it verifies the KCL at the point of common coupling.

\subsection{Unity power factor operation and harmonic analysis}

Normally in standalone DFIG-DC system, the RSC is the only source of reactive power to machine, but with the help of shunt active filter, unity power factor operation could be maintained at the point of common coupling. It is achieved by keeping the d-axis reference stator current as zero. Figure 8(a) shows uncompensated $\alpha \beta$-axis stator side currents and voltages, where $\alpha \beta$-axis currents are not exactly out of phase with $\alpha \beta$-axis voltages because of extra reactive power demand. After reactive power compensation with active filter, these currents and voltages are exactly out of phase as depicted in figure 8(d). Harmonics spectrum of a phase voltage and current before harmonic compensation is given in figure 8(b) and (c), respectively. It is shown that both waveforms have $(6 \mathrm{~K} \pm 1)$ order harmonics where, $\mathrm{K}=1,2,3 \ldots$

In this system, the most dominant harmonic component is the 5th order harmonic in the current waveform. After active filtering action, the dominant harmonics component is regulated as shown in figure 8(e) and (f). But higher order ripple content increases due to filtering limitation. The extra passive filter connection is avoided for reducing cost and size.

\subsection{Torque ripple analysis with ripple spectrum}

Experimental data of estimated torque is taken from oscilloscope and plotted in the MATLAB. The changes in the frequency of ripple are observed from figure 9(a) and

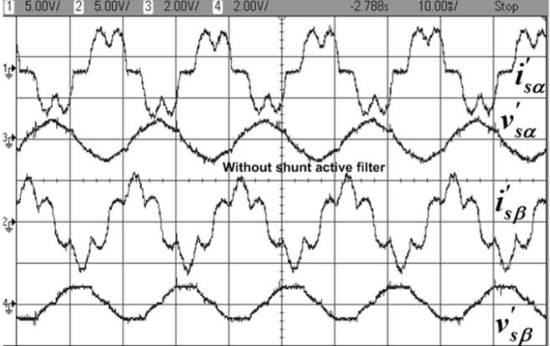

(a)

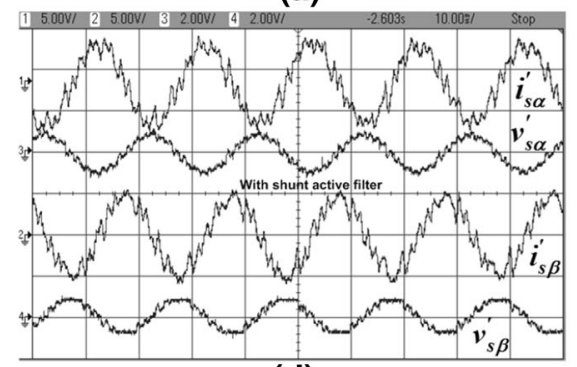

(d)

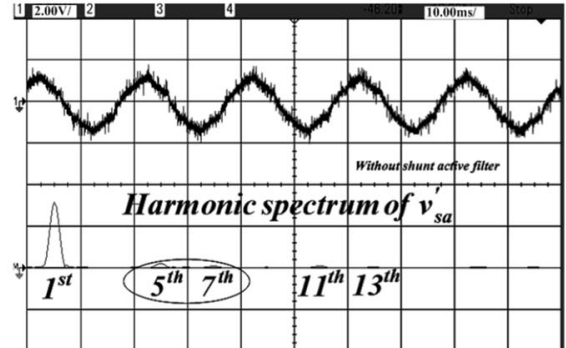

(b)

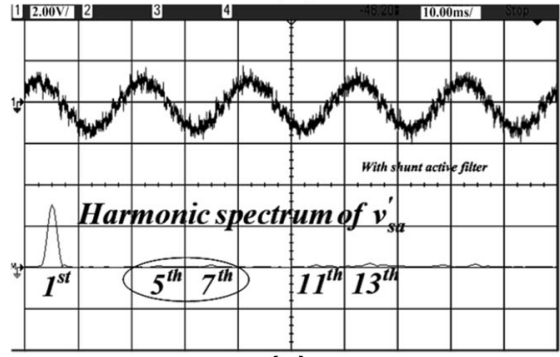

(e)

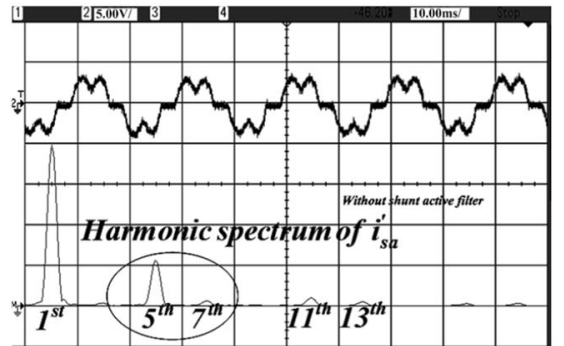

(c)

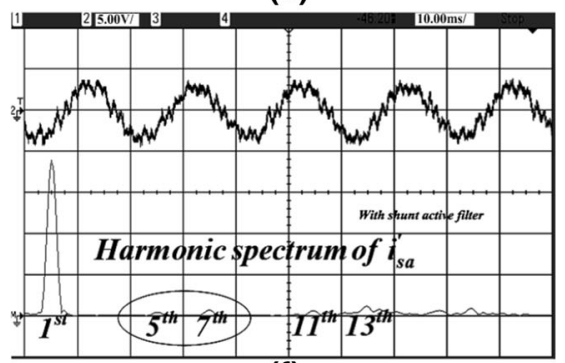

(f)

Figure 8. Experimental results showing the harmonics and reactive power compensation by shunt active filter Scale: $i_{s \alpha}{ }^{\prime}, i_{s \beta}{ }^{\prime}, i_{s a}{ }^{\prime}=$ $10.39 \mathrm{~A} / \mathrm{Div}, v_{s \alpha}{ }^{\prime}, v_{s \beta}{ }^{\prime}, v_{s a}{ }^{\prime}=135.52 \mathrm{~V} / \mathrm{Div}$, Time $=0.01 \mathrm{sec} / \mathrm{div}$. 

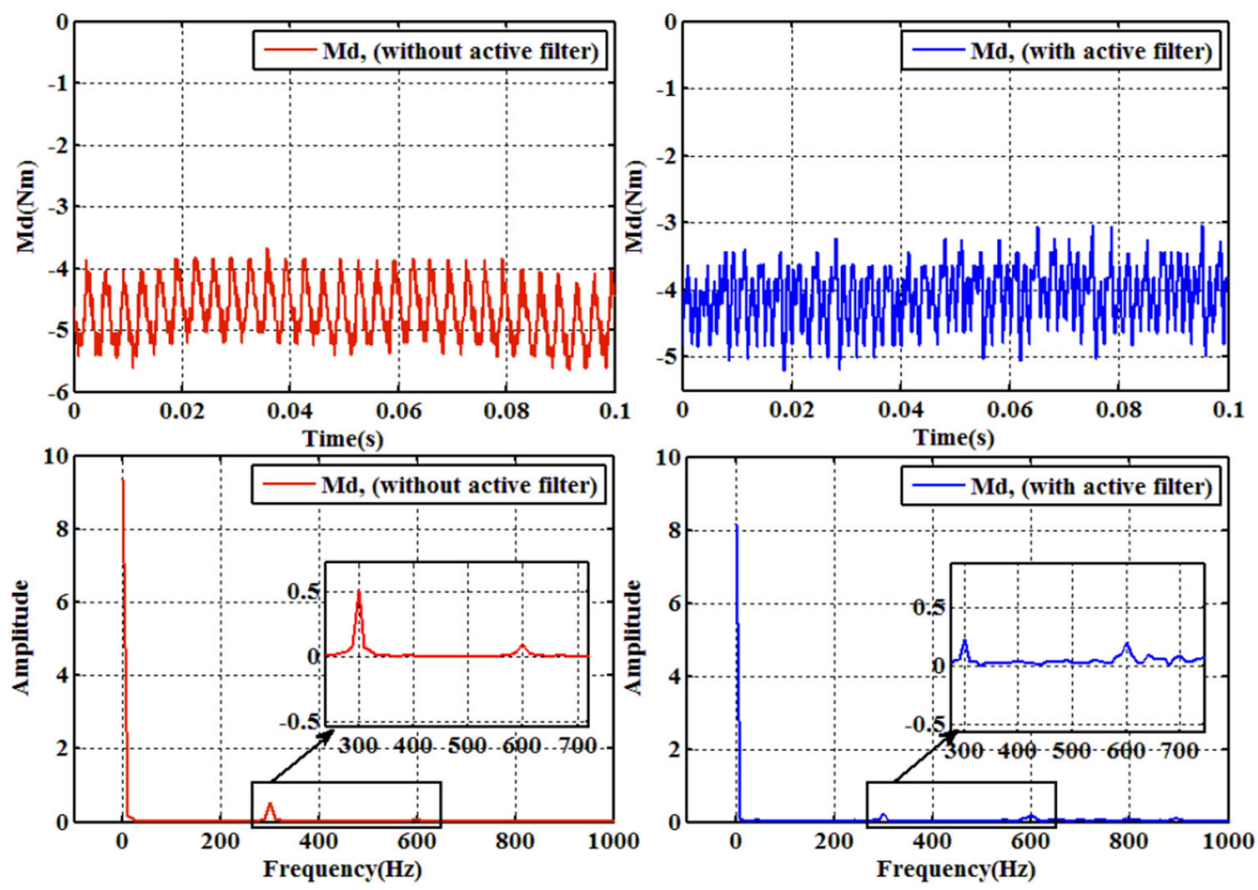

Figure 9. Torque ripple and its spectrum Scale: $M_{d}=3.5 \mathrm{Nm} / \mathrm{div}$.

(b). It is clearly seen from the ripple spectrum, plotted in figure $9(\mathrm{c})$ and (d), that the lower order ripple gets reduced to a large extent, but the higher order ripple increases, which is less dangerous for the machine.

\section{Conclusions}

In this contribution, a unique shunt active filter arrangement was proposed in standalone DFIG-DC system. The active filter assists in mitigating the lower order current harmonics generated due to the presence of diode rectifier from reaching the stator. This leads to decreased stator current and voltage harmonics as well as reduced torque ripple.

This arrangement utilizes the dc bus of the DFIG-DC system itself as input of the active filter, thus avoiding the regulation of separate dc link. Secondly, the control of active filter requires generation of unit vectors for separation of harmonic current components. This generally requires sensing of voltages at the coupling point. This requirement is also avoided in the proposed scheme, as the information of stator flux reference frame, can now be utilized for the purpose.

Experimental results supporting the operation of standalone DFIG-DC system is discussed with and without shunt active filter. The stator current waveform with filter is approaching toward sinusoidal current. The most dominant 5th order harmonic vanishes out, which is the harmful for the machine. The magnitude of torque ripple is also decreased. The, harmonic power loss is also reduced significantly. A step-down transformer is used for connecting shunt active filter to stator side. Since its leakage inductance is utilized for filtering action; hence, it gives limited filter capability. It also provides isolation from stator side, and enables DC-link sharing. Sharing of DClink gives simpler shunt active filter control due to the reduction of voltage control loop.

\section{List of symbols}

$R_{s} R_{r} \quad$ stator resistance, rotor resistance, respectively

$L_{s} L_{r} \quad$ stator inductance, rotor inductance, respectively

$L_{o} \quad$ magnetizing inductance

$\sigma_{s}, \sigma \quad$ stator leakage factor, total LEAKAGE factor

$P \quad$ number of machine poles

$v_{r d} v_{r q} \quad d$-axis, $q$-axis rotor voltage, respectively

$i_{r d} i_{r q} \quad d$-axis, $q$-axis rotor current, respectively

$v_{s d} v_{s q} \quad d$-axis, $q$-axis stator voltage, respectively

$i_{s d}^{\prime} i_{s q}^{\prime} \quad d$-axis, $q$-axis current before the active filter connecting point, respectively

$v_{s d}^{\prime} v_{s q}^{\prime} \quad d$-axis, $q$-axis stator side voltage at the active filter

$i_{m s}, i_{h}$ magnetizing current, Harmonics current

$\mu \quad$ stator flux angle

$\bar{X} \quad$ space phasor quantity

$m_{a} \quad$ modulation index

$\omega_{s} \omega_{e}$ stator frequency, prime mover frequency

$M_{d} \quad$ machine electromagnetic torque

$a b \quad$ rotor axis (rotating axis)

$d q \quad$ stator flux axis (rotating axis)

$\alpha \beta \quad$ stator axis (stationary axis) 


\section{Superscript}

$+,-5,+7 \quad(\mathrm{dq})^{+},(\mathrm{dq})^{5-}$ and $(\mathrm{dq})^{7+}$ reference frames

* reference quantity

\section{Subscript}

$+,-5,+7$ positive, negative components in respective frame

$\alpha, \beta \quad$ voltage or current in stator reference frame $(\alpha \beta)$

\section{Appendix A: Photograph of experimental set-up}

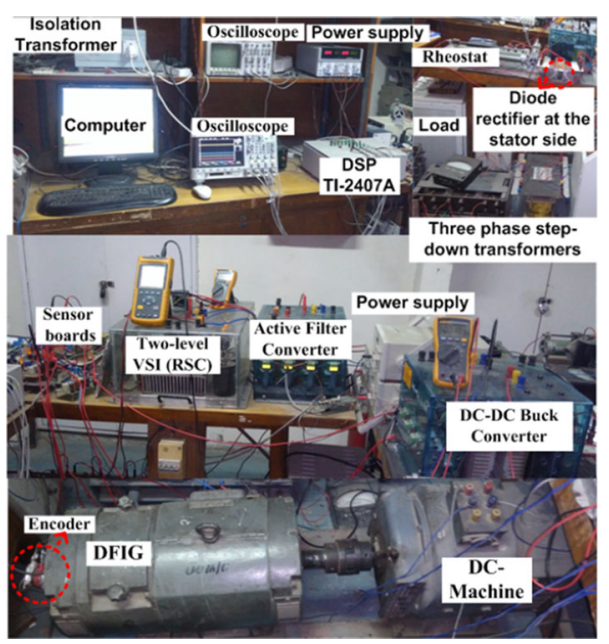

\section{Appendix B: Specifications}

WRIM Specification: $5.5 \mathrm{~kW}, 415 \mathrm{~V}, 4$-pole, 3-phase, $\mathrm{R}_{\mathrm{s}}=0.91 \Omega, \mathrm{R}_{\mathrm{r}}=1.52 \Omega, \mathrm{L}_{\mathrm{s}}=\mathrm{L}_{\mathrm{r}}=154.6 \mathrm{mH} \& \mathrm{~L}_{\mathrm{o}}=145.9 \mathrm{mH}$ STATOR: $415 \mathrm{~V}$, star connected, $7.35 \mathrm{~A}$, ROTOR: $120 \mathrm{~V}$, star connected, $42 \mathrm{~A}$.

Power Converter and Diode Rectifier: 1200 V, 100 A SEMIKRON IGBT (SKM100GB123D), SEMIKRON Bridge Rectifier Modules (MD8TU6016), DC-link capacitor $=2000 \mu \mathrm{F}$.

Transformer: $5 \mathrm{kVA}, 3$-phase, $50 \mathrm{~Hz}, 415 \mathrm{~V} / 103.75 \mathrm{~V}$, $\mathrm{R}_{\mathrm{t}}=9.4 \Omega$ and $\mathrm{L}_{\mathrm{t}}=2 \mathrm{mH}$.

DC Machine: $2.2 \mathrm{~kW}, 1650 \mathrm{rpm}$, Separately Excited Machine.

\section{References}

[1] Weichao Zhang, Haifeng Liang, Zhou Bin, Wei Li and Ran Guo 2012 Review of DC technology in future smart distribution grid. IEEE PES Innovative Smart Grid Technol. 1-4

[2] JianZ H, He Z Y, Jia J and Xie Y 2013 A review of control strategies for DC micro-grid. In: Intelligent Control and Information Proc. (ICICIP), 666-671
[3] Iacchetti M F, Marques G D and Perini R 2014 Operation and design issues of a DFIG stator-connected to a DC-net by a diode rectifier. IET Electric Power Appl. 8(8): 310-319

[4] Marques G D and Iacchetti M F 2014 Inner control method and frequency regulation of a DFIG connected to a DC Link. IEEE Trans. Energy Convers. 29(2): 435-444

[5] Marques G D, Sousa D M and Iacchetti M F 2015 Air-gap power-based sensorless control in a DFIG connected to a DC link. IEEE Trans. Energy Convers. 30(1): 367-375

[6] Iacchetti M F, Marques G D and Perini R 2015 Torque ripple reduction in a DFIG-DC system by resonant current controllers. IEEE Trans. Power Electron. 30(8): 4244-4254

[7] Yu N, Nian H and Quan Y 2011 A novel DC grid connected DFIG system with active power filter based on predictive current control. In: International Conference on Electrical Machines and Systems (ICEMS), 1-5

[8] Marques G D and Iacchetti M F 2016 Field-weakening control for efficiency optimization in a DFIG connected to a DC-link. IEEE Trans. Ind. Electron. 63(6): 3409-3419

[9] Iacchetti M F and Marques G D 2015 Voltage control in a DFIG-DC system connected to a stand-alone dc load. In: 9 th International Conference on Compatibility and Power Electronics (CPE), 323-328

[10] Misra H, Gundavarapu A and Jain A K 2017 Control scheme for DC voltage regulation of stand-alone DFIG-DC system. IEEE Trans. Ind. Electron. 64(4): 2700-2708

[11] Marques G D and Iacchetti M F 2017 Sensorless frequency and voltage control in stand-alone DFIG-DC system. IEEE Trans. Ind. Electron. 64(3): 1949-1957

[12] Misra H and Jain A K 2017 Analysis of stand alone DFIGDC system and DC voltage regulation with reduced sensors. IEEE Trans. Ind. Electron. 64(6): 4402-4412

[13] Van-Tung P and Hong-Hee L 2011 Control strategy for harmonic elimination in stand-alone DFIG applications with nonlinear loads. IEEE Trans. Power Electron. 26(9): 2662-2675

[14] Singh B, Al-Haddad K and Chandra A 1999 A review of active filters for power quality improvement. IEEE Trans. Ind. Electron. 46(5): 960-971

[15] Bhattacharya S, Frank T M, Divan T M and Banerjee B 1998 Active filter system implementation. IEEE Industry Appl. Mag. 4(5): 47-63

[16] Bhattacharya S, Veltman A, Divan D M and Lorenz R D 1996 Flux-based active filter controller. IEEE Trans. Industry Appl. 32(3): 491-502

[17] Bhattacharya S and Divan D 1995 Synchronous frame based controller implementation for a hybrid series active filter system. In: IEEE Industry Applications Conference, Thirtieth IAS Annual Meeting. 3: 2531-2540

[18] Peng F Z 1998 Application issues of active power filters. IEEE Industry Appl. Mag. 4(5): 21-30

[19] Gonzalo A, Lopez J, Rodriguez M, Marroyo L and Iwanski G 2011 Doubly fed induction machine: modeling and control for wind energy generation, Hoboken, NJ, USA: Wiley-IEEE Press

[20] Pena R, Clare J C and Asher G M 1996 A doubly fed induction generator using back-to-back PWM converters supplying an isolated load from a variable speed wind turbine. IEE Proc. Electric Power Appl. 143(5): 380-387

[21] Cardenas R, Pena R, Proboste J, Asher G and Clare J 2005 MRAS observer for sensorless control of standalone doubly fed induction generators. IEEE Trans. Energy Convers. 20(4): 710-718 
[22] Cardenas R, Pena R, Alepuz S and Asher G 2013 Overview of control systems for the operation of DFIGs in wind energy applications. IEEE Trans. Ind. Electron. 60(7): 2776-2798

[23] Jain A K and Ranganathan V T 2008 Wound rotor induction generator with sensorless control and integrated active filter for feeding non-linear load in a stand-alone grid. IEEE Trans. Ind. Electron. 55(1): 218-228

[24] Sam K N, Kumaresan N and Gounden N A 2017 Winddriven stand-alone DFIG with battery and pumped hydro storage system. Sādhanā 42(1): 173-185 